\title{
Well-defined side-chain liquid-crystalline polysiloxanes
}

\author{
Mark A. Hempenius, Rob G. H. Lammertink, G. Julius Vancso* \\ University of Twente, P.O. Box 217, 7500 AE Enschede, The Netherlands
}

(Received: February 7, 1996)

\section{SUMMARY}

A route to well-defined side-chain liquid-crystalline polysiloxanes (ratio of weight- to number-average molar masses $\bar{M}_{\mathrm{w}} / \bar{M}_{\mathrm{n}}<1.2$ is reported. Anionic ring-opening polymerization of pentamethylvinylcyclotrisiloxane yielded a poly(dimethylsiloxane-co-methylvinylsiloxane) backbone. A flexible disiloxane spacer was used to connect $4-(\omega$-alkenyloxy)-4'-cyanobiphenyl mesogenic molecules to the vinyl groups which belong to the backbone, leading to a side-chain liquid-crystalline polysiloxane (SCLCP) which has its mesogens distributed regularly along the main chain. Preliminary measurements indicate an electro-optic switching time $\tau_{\mathrm{s}}=1 \mathrm{~min}$ at $20^{\circ} \mathrm{C}$ and $7 \mathrm{~s}$ at $32^{\circ} \mathrm{C}(\mathrm{dc}, 5 \mathrm{~V} / \mu \mathrm{m})$.

\section{Introduction}

Side-chain liquid-crystalline polysiloxanes (SCLCPs) have attracted much interest since their appearance in the literature in $1980^{1}$, , because of their potential use as, for example, laser-writable optical recording devices ${ }^{2)}$ and stress sensors ${ }^{3)}$. Since their discovery, SCLCPs have been obtained by preparing a SiH-containing main chain onto which vinyl-containing mesogenic molecules were attached by means of a hydrosilylation reaction ${ }^{4}$ (schematic Eq. (1)).

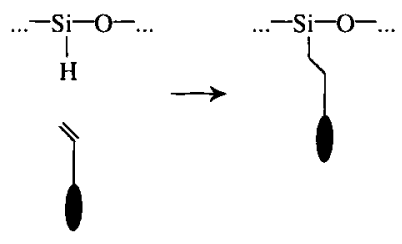

The main chain is usually prepared by acid-catalyzed equilibration polymerizations $^{4.5)}$ of 1,3,5,7-tetramethylcyclotetrasiloxane, or mixtures of this tetramer and octamethylcyclotetrasiloxane. This cationic route to poly(hydrogenmethyl)siloxanes and poly(dimethylsiloxane-co-hydrogenmethylsiloxane) leads to polymers with broad molar mass distributions (ratio of weight- to number-average molar masses $\left.2 \leqslant \bar{M}_{\mathrm{w}} / \bar{M}_{\mathrm{n}} \leqslant 3\right)^{4-6)}$ and the formation of cyclic oligomers which cannot readily be separated from the desired linear polymers. In the case of the widely used copolymers, a non-statistical distribution of $\mathrm{SiH}$ units may occur, causing the formation of block as opposed to random sequences of monomeric units, which influences the thermal properties ${ }^{7}$. Commercially available SiH-containing polysiloxanes also have the above-mentioned broad molar mass distributions and microstructure variations. 
Both applications and structure-property studies benefit from SCLCPs, which have a controlled molar mass, molar mass distribution and microstructure. This prompted us to develop a novel route to these intriguing materials. In this communication we report on the synthesis of low glass transition temperature and welldefined side-chain liquid-crystalline polysiloxanes.

\section{Experimental part}

All reactions were carried out under argon. $N, N$-dimethylformamide (DMF) was dried over molecular sieves $(3 \AA)$, and tetrahydrofuran (THF) and toluene were distilled from potassium-benzophenone under argon. The platinum-cyclovinylmethylsiloxane catalyst PC085 (3-3.5 wt.-\% Pt) was obtained from ABCR Karlsruhe.

Characterization: Gel-permeation chromatography (GPC) measurements were carried out in THF using microstyragel columns with pore sizes of $10^{5}, 10^{4}, 10^{3}$ and $10^{6} \AA$ (Waters), a dual detection system consisting of a differential refractometer (Waters model 410 ) and a differential viscometer (Viscotek model H502). Elution volumes were correlated to polystyrene-effective molar masses $(\mathrm{g} / \mathrm{mol}$ ) by means of a calibration based on polystyrene standards, using UNICAL software. A Perkin-Elmer DSC-7 equipped with a PE-7700 computer and TAS-7 software was used to monitor thermal transitions. ${ }^{1} \mathrm{H}$ Nuclear magnetic resonance (NMR) spectra were recorded on a Bruker AC 250 spectrometer at $250.1 \mathrm{MHz},{ }^{29} \mathrm{Si}$ NMR spectra on a Varian Unity $400 \mathrm{WB}$ spectrometer at 79.5 $\mathrm{MHz}$.

Pentamethylvinylcyclotrisiloxane (2): 1,1,3,3-Tetramethyldisiloxane was converted to tetramethyldisiloxane-1,3-diol $(\mathbf{1})^{8)}$, using $\mathrm{Pd} / \mathrm{C}$ as catalyst. Heterofunctional condensation $^{9)}$ of this diol with dichloromethylvinylsilane in diethyl ether and triethylamine resulted in 2 (b.p. $\left(14 \mathrm{mmHg}\right.$ ): $45-50^{\circ} \mathrm{C}$ ). Yield: $50 \%$, based on the diol.

${ }^{1} \mathrm{H}$ NMR $\left(\mathrm{CDCl}_{3}\right): \delta=0.00(\mathrm{~s}, 12 \mathrm{H}, 3+3+5+5-\mathrm{Me}), 0.06$ (s, 3H, 1-Me), 5.64-5.90 (m, 3H, 1-Vinyl).

Poly(dimethylsiloxane-co-methylvinylsiloxane) (3): Compound $2(26.5 \mathrm{~g}, 113 \mathrm{mmol})$ in THF (20 mL) was added to a solution of lithium trimethylsilanolate $(2.83 \mathrm{mmol})$ in dry THF $(20 \mathrm{~mL})^{\prime}$ at $0^{\circ} \mathrm{C}$ under argon. The mixture was stirred in an ice bath for $24 \mathrm{~h}$. Then, DMF ( $5 \mathrm{~mL})$ and tert-butyldimethylsilyl chloride $(0.85 \mathrm{~g}, 5.64 \mathrm{mmol})$ were added, and the ice bath was removed. After stirring for $24 \mathrm{~h}$, the solution was concentrated and the polymer was precipitated in methanol $(200 \mathrm{~mL})$ containing triethylamine $(5 \mathrm{~mL})$, in methanol $(2 \times)$, and dried in vacuum.

${ }^{\mathrm{l}} \mathrm{H}$ NMR $\left(\mathrm{CDCl}_{3}\right): \delta=0.00\left(\mathrm{~s}, \mathrm{SiMe}_{2}\right), 0.06$ (s, $\left.\mathrm{MeSiVi}\right), 0.79$ (s, Si-t-Bu), 5.66-6.00 (m, MeSiVi).

4-Cyano-4'-( $\omega$-alkenyloxy)biphenyls: Deprotonation of 4-cyano-4'-hydroxybiphenyl by sodium hydride in THF/DMF ( $3: 1$ by volume), followed by alkylation at $60^{\circ} \mathrm{C}$ with 4-pentenyl methanesulfonate or 9-decenyl methanesulfonate (from the corresponding alcohols and methanesulfonyl chloride in pyridine), and purification by means of column chromatography ( $\mathrm{SiO}_{2}$-toluene), produced the mesogenic molecules. Yield: 90-95\%.

Side-chain liquid-crystalline polysiloxanes (4): Reaction of a 4-cyano-4'-( $\omega$-alkenyloxy)biphenyl $(11.4 \mathrm{mmol})$ in toluene $(20 \mathrm{~mL})$ with $1,1,3,3$-tetramethyldisiloxane $(0.22$ mol) at $50-60^{\circ} \mathrm{C}$, using the platinum-cyclovinylmethylsiloxane catalyst PC085 (1 drop), gave complete conversion in $20 \mathrm{~h}$. The excess of disiloxane was removed, as well as the toluene, by flushing with argon or by distillation in vacuum. Fresh toluene $(10 \mathrm{~mL})$ was added, and the flushing was repeated. A solution of polysiloxane $3(2.27 \mathrm{~g}, 9.7 \mathrm{mmol}$ vinyl) in toluene $(15 \mathrm{~mL})$ was added to the residue, along with a drop of catalyst, and the mixture was heated at $50-60^{\circ} \mathrm{C}$ for $20 \mathrm{~h}$. Purification by column chromatography $\left(\mathrm{SiO}_{2}-\right.$ 
toluene) and elution of the SCLCP with diethyl ether, followed by precipitation in methanol, produced pure materials. Yield: $80-90 \%$, based on 3 .

\section{Results and discussion}

In general, siloxane polymers with controlled molar masses and a narrow molar mass distribution are prepared by anionic ring-opening polymerization of cyclotrisiloxanes $^{4}$. The anionic polymerization of a vinyl-functionalized cyclotrisiloxane yielded a chain with regularly spaced pendant vinyl groups. Vinyl-containing mesogens were attached to the polysiloxane vinyl groups by means of the well-known, highly efficient hydrosilylation reaction, using the difunctional linker molecule 1,1,3,3-tetramethyldisiloxane (schematic Eq. (2)).

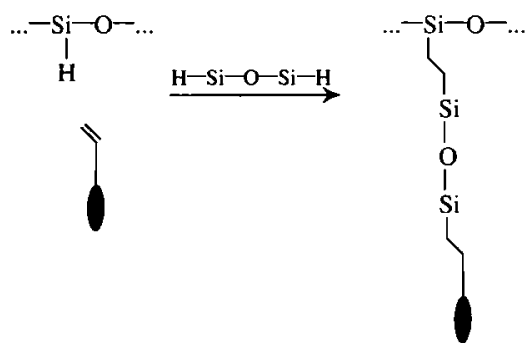

A heterofunctional condensation ${ }^{9)}$ of 1,1,3,3-tetramethyl-1,3-disiloxanediol (1) and dichloromethylvinylsilane yielded pentamethylvinylcyclotrisiloxane (2), which was polymerized in THF to poly(dimethylsiloxane-co-methylvinylsiloxane) (3), using lithium trimethylsilanolate as initiator and tert-butyldimethylsilyl chloride to end-cap the living chains (Scheme 1). The end-cap reaction was found to proceed quantitatively in the presence of DMF. Based on the ratio of monomer to initiator, a number-average degree of polymerization $\bar{X}_{n}$ of 120 was expected.

Polysiloxane 3 was characterized by means of gel-permeation chromatography (GPC) and ${ }^{1} \mathrm{H}$ nuclear magnetic resonance (NMR). The polystyrene-effective molar

\section{Scheme 1:}

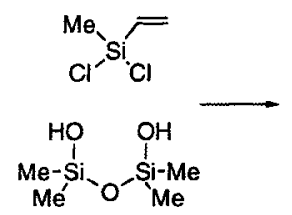

1

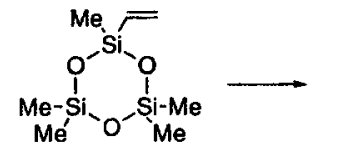

2

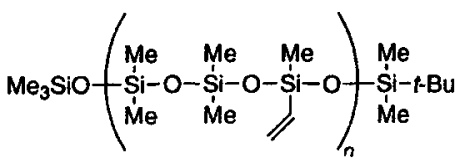

3

Me: $\mathrm{CH}_{3}$

$t-\mathrm{Bu}: \mathrm{C}\left(\mathrm{CH}_{3}\right)_{3}$ 
mass obtained from GPC agrees with the $\bar{X}_{n}$ calculated from the ratio of vinyl to tert-butyl signal in the ${ }^{1} \mathrm{H}$ NMR spectrum (Tab. 1 ).

${ }^{29} \mathrm{Si}$ NMR analysis showed that the microstructure of $\mathbf{3}$ is predominantly alternating.

Tab. 1. Characteristics of poly(dimethylsiloxane-co-methylvinylsiloxane) $3^{\text {a) }}$

\begin{tabular}{|c|c|c|c|c|}
\hline \multicolumn{3}{|c|}{$\mathrm{GPC}^{\mathrm{b})}$} & \multicolumn{2}{|c|}{${ }^{\mathrm{l}} \mathrm{H} \mathrm{NMR}^{\mathrm{c})}$} \\
\hline $\bar{M}_{\mathrm{w}}$ & $\bar{M}_{\mathrm{n}}$ & $\bar{M}_{\mathrm{w}} / \bar{M}_{\mathrm{n}}$ & $\bar{M}_{\mathrm{n}}$ & $\bar{X}_{\mathrm{n}}$ \\
\hline 10770 & 9054 & 1.16 & 10900 & 140 \\
\hline
\end{tabular}

a) Based on the ratio of monomer to initiator, a number-average degree of polymerization $\bar{X}_{n}=120$ was expected.

b) Gel-permeation chromatography (GPC) measurements in tetrahydrofuran, polystyrene-effective weight-average and number-average molar masses $\bar{M}_{\mathrm{w}}$ and $\bar{M}_{\mathrm{n}}$.

c) Proton nuclear magnetic resonance ( ${ }^{1} \mathrm{H}$ NMR) measurements based on the ratio of the vinyl to tert-butyl integral; $\bar{X}_{\mathrm{n}}$ is number-average degree of polymerization

Several mesogenic molecules, for example 4-cyano-4'-( $\omega$-alkenyloxy)biphenyls, were readily grafted onto 3 (Scheme 2 ). The mesogens were first allowed to react with an excess of 1,1,3,3-tetramethyldisiloxane, which was removed by flushing

Scheme 2:

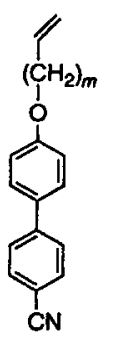

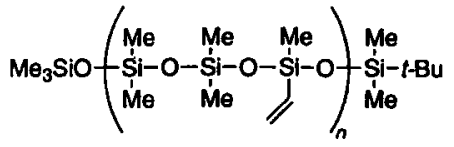

3

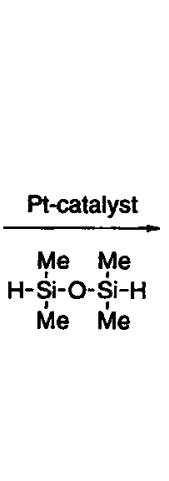

\section{Pt-catalyst}<smiles>C[Si](C)(C)O[Si](C)(C)COc1ccc(-c2ccc(C#N)cc2)cc1</smiles>

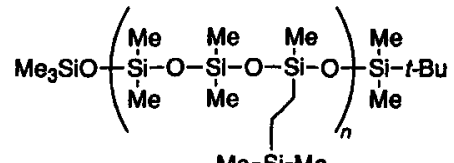

Me-Si-Me

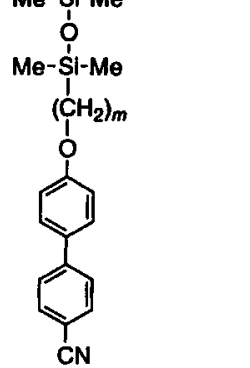

4

$$
\begin{gathered}
\mathrm{Me}: \mathrm{CH}_{3} \\
t-\mathrm{Bu}: \mathrm{C}\left(\mathrm{CH}_{3}\right)_{3}
\end{gathered}
$$


with inert gas or by distillation in vacuum. Subsequently, polysiloxane $\mathbf{3}$ in toluene was added. Both hydrosilylation reactions went to completion, as was evident from the disappearance of the corresponding vinyl signals in the ${ }^{1} \mathrm{H}$ NMR spectra.

After purification, SCLCPs 4 were obtained in $80-90 \%$ yield (based on 3). The SCLCPs showed the same narrow molar mass distribution $\left(1.15 \leqslant \bar{M}_{\mathrm{w}} / \bar{M}_{\mathrm{n}} \leqslant 1.18\right)$ as the backbone 3 , and have the same regular distribution of pendant groups along the chain. The materials (Scheme 2, with $m=5,10$, and with an equimolar mixture of $m=5$ and 10) have a glass transition temperature of $-42^{\circ} \mathrm{C}$.

Preliminary evidence shows that the flexible disiloxane link strongly increases the mobility of the mesogenic molecules. A SCLCP which contained cyanobiphenyl mesogens with different spacer lengths $(4, m=5$ and 10 , equimolar amounts) could readily be oriented in an electric field. An electro-optic switching time ${ }^{(0)} \tau_{\mathrm{s}}$ of $1 \mathrm{~min}$ at $20^{\circ} \mathrm{C}$, and $7 \mathrm{~s}$ at $32^{\circ} \mathrm{C}(\mathrm{dc}, 5 \mathrm{~V} / \mu \mathrm{m})$ was achieved. Up to now, SCLCPs only showed similar times at elevated temperatures $\left(60-80^{\circ} \mathrm{C}\right)^{10.11)}$. This important aspect $^{12)}$ is presently under investigation.

We thank O.F.J. Noordman (University of Twente) for assistance with the electrooptic measurements. Financial support from the University of Twente is gratefully acknowledged.

") H. Finkelmann, G. Rehage, Makromol. Chem., Rapid Commun. 1, 31 (1980)

2) H. J. Coles, R. Simon, Polymer 26, 1801 (1985)

3) C. B. McArdle, Ed., "Side-chain Liquid Crystal Polymers", Chapman \& Hall, New York 1989

4) M.S. White, in: "Siloxane Polymers", S. J. Clarson and J. A. Semlyen, Eds., Prentice Hall, Englewood Cliffs 1993, chap. 6

5) Y. Chujo, K. Murai, Y. Yamashita, Y. Okumura, Makromol. Chem. 186, 1203 (1985)

6) G. W. Gray, W. D. Hawthorne, J. S. Hill, D. Lacey, M. S. K. Lee, G. Nestor, M. S. White, Polymer 30, 964 (1989)

7) H. Ringsdorf, A. Schneller, Makromol. Chem., Rapid Commun. 3, 557 (1982)

8) G. H. Barnes, Jr., N. E. Daughenbaugh, J. Org. Chem. 31, 885 (1966)

9) Yu. A. Yuzhelevskii, T. V. Kurlova, E. G. Kagan, M. V. Suvorova, Zh. Obshch. Khim. 42, 2006 (1972); Chem. Abstr. 79, 29873h (1973)

10) H. J. Coles, Faraday Discuss. Chem. Soc. 79, 201 (1985)

11) G. Williams, A. Nazemi, F. E. Karasz, Macromol. Rep. A31, 911 (1994) and refs. cited therein

12) J. Abe, M. Hasegawa, H. Matsushima, Y. Shirai, N. Nemoto, Y. Nagase, N. Takamiya, Macromolecules 28, 2938 (1995) 